\section{PRACTICE OF MEDICINE IN THE UNITED STATES}

N January, I943, the Council of the New York
Academy of Medicine appointed a Committee on
Medicine and the Changing Order, which was charged
with the study of the economic and social changes
which are now taking place or are likely to occur in
the future, with the question of how these changes
may affect medicine and how the best possible
medical care may be made available to the largest
number of people at the lowest possible cost. This
Committee, composed of representatives of the
physicians, dentists and nurses and of laymen
belonging to industry and various professions, has
issued an interim report ( 2 East I03rd St., New York,
1945). A final report is expected early in 1946.
During its twenty-two months of activity, the
Committee held weekly conferences at which it was
addressed by experts. The list of speakers shows
that a wide field was covered, for economists, his-
torians, publicists, bankers, industrialists and repre-
sentatives of labour were among those invited. Other
weekly conferences studied medical education, hos-
pital problems, rural and industrial medicine, public
health and problems of dentistry and nursing.
Monographs on major current socio-medical problems
were planned to treat contemporary medicine in all
its aspects, and some of these are well on the way
towards completion; someshort treatises havealready
been published.

Defining its approach to its problems, the Committee states that medicine carries definite moral and social responsibilities. Modern medical problems have been accentuated by recent economic and social dislocations and have been long in the making. Complicated and costly as its administrative structure now is, medicine has its own history and has continuously tried to improve its science and practice. It has largely depended upon benevolence and charity; this dependence has benefited it, but has created many of its present difficulties. Medicine obviously cannot, without great harm, allow its progress to be governed by profit and loss, and it cannot compromise with quality. There is a widespread demand for good medical care which costs as little as possible, so that medicine cannot continue to work as it has done. If the quality of medicine is to be maintained, medical education and research are basic problems, and laymen must understand. what medical education involves. The present curriculum needs revision. Its duration is ever increasing, so that from seven to nine years are spent in training and often several more years in specialized study, so that the medical man begins practice at an advanced age with a large capital investment and a relatively short time in which to recover it. These problems are more important than they appear, and efforts must be made to enable the medical practitioner to become productive earlier without adversely affecting his training. The rapidity of scientific development imposes an increased need for postgraduate education and refresher courses, and this need will increase in the future.

The quality of medical practice is also largely dependent upon public understanding and demand, so that people cannot obtain the full advantages of modern medicine without the intelligent and informed co-operation of the public. Hospitals present major problems. They not only treat the sick, but have also essential educational functions, and any changes made in hospital organization involve numerous factors. The medical man, moreover, nowadays does more than treat the sick; he may look after those who are well, or serve schools, industry, insurance companies, public health and so on; all these activities need planning according to possible future developments. Preventive medicine must also be carefully planned. The economic problems of medicine are complex, but real economy in medical care comes from the quality and competence of the treat. ment rather than from expenditure upon illness. It is therefore likely that better treatment, even though it costs more, will be the cheaper in the long run. Fewer illnesses rather than lower fees may prove to be the solution.

Current efforts to cure human ills by massive doses of social legislation are full of great dangers, the greatest being the fact that laudable ends will be betrayed by incompetent means used to gain them. Social legislation has, in itself, no power; it must have practical ends and means. Based upon wishful thinking, it can be harmful. We need precise definition of the factors involved and workable proposals which will effect progress. Experiments in various forms of medical care must obviously be undertaken before legislation is attempted.

With all these principles and attitudes of mind, somewhat nebulous though they are, many British medical men will agree. Most of them are, indeed, reflected in recent British plans for the reform of medical education which have been noticed in these columns (see, for example, the report of the Goodenough Committee on Medical Schools and the report of the Committee of the Royal College of Physicians of London, Nature, 154, 315 and 322 ; 1.944). Everywhere in the world the problems confronting this Cornmittee in the United States are demanding attention. It is good to know that most of those who are dealing with them are agreed that, in the future, medical care must be the best that is possible, and at the lowest cost; and that, above all, the freedom of the medical man to act and of the patient to consult whom he likes must be preserved.

\section{OCEANOGRAPHICAL RESULTS OF THE LAST VOYAGE OF THE U.S. NON-MAGNETIC SHIP CARNEGIE}

$\mathrm{T}$

HE Carnegie Institution of Washington is issuing a series of reports on the scientific results of the last voyage of the Carnegie, and has recently published. the first two of the series to deal with physical and chemical oceanography ${ }^{1}$. The voyage was started in May 1928, and was brought to a tragic end after 18 months, when the vessel was destroyed by fire. A general account of the voyage was published by the ship's surgeon in $1932^{2}$. One cruise was made in the North Atlantic Ocean, and extensive voyages in the Pacific Ocean, crossing most areas north of $40^{\circ} \mathrm{S}$. in the east, and $10^{\circ} \mathrm{N}$. in the west.

The publication of both reports has been long delayed. Dr. Sverdrup's chapters on the North Atlantic and Pacific Oceans were written in 1931, and although some revision has been possible, it is not sufficient to take all subsequent work into considera- 